\title{
Patient preferences for chemotherapies used in breast cancer
}

This article was published in the following Dove Press journal:

International Journal of Women's Health

27 June 2012

Number of times this article has been viewed

\author{
Kathleen Beusterien' \\ Jessica Grinspan' \\ Thomas Tencer ${ }^{2}$ \\ Adam Brufsky ${ }^{3}$ \\ Constance Visovsky ${ }^{4}$ \\ 'Oxford Outcomes Inc, an ICON \\ plc company, Bethesda, MD, \\ ${ }^{2}$ Eisai Inc, Woodcliff Lake, NJ, \\ ${ }^{3}$ University of Pittsburgh Cancer \\ Institute, Pittsburgh, PA, \\ ${ }^{4}$ University of South Florida, College \\ of Nursing, Tampa, FL, USA
}

Background: Therapies for invasive breast cancer may be associated with an incremental survival advantage that should be weighed against the risk of toxicities when making treatment decisions. The objective of this study was to elicit patient preferences for a comprehensive profile of attributes associated with chemotherapies for breast cancer.

Methods: This was a cross-sectional study of 121 patients with stage I-IV breast cancer who completed an internet-based conjoint survey that assessed the following attributes: ten grade III/IV toxicities, survival advantage, and administration regimen. Literature and expert input were used to identify descriptions for each attribute and respective levels (eg, different risks of toxicities). Subjects rated the attribute levels on a series of scales and indicated preferences in pair-wise comparisons of two hypothetical treatments differing in attribute levels. Ordinary leastsquares regression was used to calculate utilities (preference weights) for each attribute level. Results: Of the twelve attributes, survival was the most important; specifically, a survival advantage of 3 months versus no survival advantage was most influential in the perceived value of chemotherapy. Among toxicities, the differences in the risks of neutropenia with hospitalization, diarrhea, nausea, and fatigue had the most impact on preferences; the risk differences of myalgia, stomatitis, and hand-foot syndrome had the least. In general, a more convenient administration regimen was less important than a $13 \%$ chance or more of severe toxicities, but more important than a $10 \%-12 \%$ chance of severe toxicities.

Conclusion: Breast cancer patients place high value on small incremental survival advantages associated with treatment despite the risk of serious toxicities.

Keywords: preferences, conjoint, breast cancer, chemotherapy, toxicity

\section{Introduction}

Breast cancer is the second most common cancer among women in the United States, with approximately 54,010 new cases of carcinoma in situ (noninvasive cancer) and 207,090 cases of invasive cancer diagnosed per year. In addition, breast cancer is the second leading cause of cancer death in women, with about 39,840 deaths occurring per year. ${ }^{1}$ Five-year survival rates vary by stage: the 5 -year survival rate for patients with stage 0 through stage IIA breast cancer ranges from 92 to $100 \%$, while the 5 -year survival rate for patients with stage IV metastatic breast cancer is approximately $20 \%{ }^{1}$ Thus, the goal of therapy for invasive breast cancer is primarily palliative - that is, aimed at alleviating and controlling symptoms as well as improving quality of life. ${ }^{2}$ Treatments in common use for invasive breast cancer include cytotoxic chemotherapy, hormonal treatments, and targeted therapies/biologics, which can be administered as single agents or in combination with each other. ${ }^{3}$
Correspondence: Kathleen Beusterien 7315 Wisconsin Ave, Ste 250W Bethesda, MD 208I4, USA

$\mathrm{Tel}+\mathrm{I} 30$ I 84I 3858

Fax +I 2404820043

Email kathy.beusterien@

oxfordoutcomes.com 
Given that current chemotherapies have advantages or disadvantages relative to each other, it would be useful to understand how these influence patient preferences for treatment. Some studies have examined patient preferences with respect to chemotherapy toxicities. For example, one recent study evaluated preferences for health states associated with chronic lymphocytic leukemia treatments using the standard-gamble method. ${ }^{4}$ Other studies have also examined patient preferences for select groups of chemotherapy toxicities. ${ }^{5,6}$ However, to date, no study has evaluated the importance of toxicities relative to other characteristics such as efficacy and administration. Conjoint analysis, which is increasingly being used in evaluating medical interventions, involves respondents making trade-offs among product features (attributes) such as mode of administration and risk of adverse events. ${ }^{78}$ The resulting data, or utilities, enable the assessment of the relative importance of each treatment attribute; specifically, they show the influence that each attribute has on overall treatment preferences.

The goal of the present study was to use conjoint analysis to capture patient preferences for attributes associated with chemotherapies for invasive breast cancer. Specifically, the survey aimed to assess the trade-offs that breast cancer patients are willing to make among chemotherapies according to different toxicity, regimen, and efficacy profiles.

\section{Methods}

This was a cross-sectional, internet-based survey assessing the chemotherapy treatment preferences of women with breast cancer. Study participants were recruited through newspaper advertisements and online breast cancer support forums. All participants were women with United States residency; at least 18 years of age; had a diagnosis of stage I through IV breast cancer; had received chemotherapy treatment within the past 5 years; and provided informed consent and Health Insurance Portability and Accountability Act-compliant Authorization. ${ }^{9}$ Participants completed the survey at home and worked at their own pace. However, research team members were available via telephone or email to answer questions or provide technical help if necessary. Participants were compensated US $\$ 30.00$ for their time. The study followed the tenets of the Declaration of Helsinki, and the protocol was approved by a commercial institutional review board (Independent IRB; Plantation, FL). This research was implemented following published methodological guidelines for conjoint studies. ${ }^{10}$ The survey design and analysis are detailed below.

\section{Survey design}

Twelve attributes of eight invasive breast cancer chemotherapy treatments were identified from a comprehensive literature review, the Common Toxicity Criteria grading system, a detailed assessment of breast cancer forum discussions, and consultation with clinical experts. These attributes included selected grade III/IV toxicities, efficacy (survival advantage), and regimen. Attributes were described in lay terminology so that they could be easily understood by patients. Each attribute was presented in different levels that represented the full range of possibilities across available breast cancer treatments. Each toxicity attribute had three levels. Based on the literature and clinician input, potential ranges for the incidence of each of the toxicities were identified, and these were used as the most favorable and least favorable levels, respectively. The regimen attribute had six levels, each describing a different chemotherapy regimen. Table 1 presents the attributes and the respective levels used in the survey.

An adaptive conjoint analysis (ACA) approach was used to design the survey. This involves a hybrid approach, in which the data are collected in phases. ${ }^{11,12}$ The respondent completes the ACA computer-assisted questionnaire, and the questionnaire is modified during the responding process on the basis of the respondent's previous choices. Thus the interview can focus on just those attributes that the respondent considers most important and those attribute levels regarded as most relevant. In the first phase, respondents were asked to rate the levels of each attribute in terms of acceptability on a 7-point scale, from 1, "not at all acceptable", to 7, "acceptable". The second phase (paired comparison questions) elicited treatment preferences by asking respondents to make trade-offs among attributes and choose from a pair of hypothetical treatments. In each of these questions, the profiles of two hypothetical treatments - labeled simply chemotherapy A and chemotherapy B - were presented with different levels of the same three attributes (no chemotherapies were named in the survey). Respondents used a 7-point scale to indicate not only their preference, but the strength of their preference; response options ranged from "strongly prefer A" to "strongly prefer B". The profiles presented to respondents in this second phase were customized based on responses to previous questions. The final section of the survey contained demographic and clinical questions. The survey was pilot-tested with respect to wording and comprehension in a sample of four breast cancer patients; no major changes were necessary. 
Table I Attributes and respective levels presented in conjoint survey

\begin{tabular}{|c|c|c|c|}
\hline Attribute and description (labels not shown in survey) & Level \# I & Level \#2 & Level \#3 \\
\hline \multicolumn{4}{|l|}{ Alopecia } \\
\hline $\begin{array}{l}\text { Chance of losing most or all of your hair, thinning of eyebrows/eye lashes; } \\
\text { starts to grow back within 2-3 months after receiving chemotherapy. }\end{array}$ & $0 \%$ & $48 \%$ & $94 \%$ \\
\hline \multicolumn{4}{|l|}{ Grade III/IV sensory neuropathy } \\
\hline $\begin{array}{l}\text { Chance of severe numbness, sharp tingling (pins and needles), and burning } \\
\text { sensation in arms and legs, interfering with daily tasks like holding a pen, } \\
\text { dressing, or cooking; may last } 6 \text { months after receiving chemotherapy. }\end{array}$ & $0 \%$ & $7 \%$ & $13 \%$ \\
\hline \multicolumn{4}{|l|}{ Grade III/IV motor neuropathy } \\
\hline $\begin{array}{l}\text { Chance of feeling very weak, shaky, and unsteady, making it difficult to hold } \\
\text { objects and requiring a cane or other assistance; may last } 6 \text { months after } \\
\text { receiving chemotherapy. }\end{array}$ & $0 \%$ & $4 \%$ & $10 \%$ \\
\hline \multicolumn{4}{|l|}{ Grade III/IV myalgia/arthralgia } \\
\hline $\begin{array}{l}\text { Chance of severe joint/muscle aches, pain, and stiffness, making it difficult } \\
\text { to move; may last up to } 4-7 \text { days after receiving chemotherapy. }\end{array}$ & $0 \%$ & $4 \%$ & $15 \%$ \\
\hline \multicolumn{4}{|l|}{ Grade III/IV nausea and vomiting } \\
\hline $\begin{array}{l}\text { Chance of severe nausea and/or vomiting requiring intravenous fluids at the } \\
\text { doctor's office or ER; may last 2-3 days after receiving chemotherapy. }\end{array}$ & $0 \%$ & $4 \%$ & $15 \%$ \\
\hline \multicolumn{4}{|l|}{ Grade III/IV fatigue } \\
\hline $\begin{array}{l}\text { Chance of severe fatigue, making it difficult to perform daily activities; } \\
\text { may last } 6 \text { months after receiving chemotherapy. }\end{array}$ & $0 \%$ & $8 \%$ & $24 \%$ \\
\hline \multicolumn{4}{|l|}{ Grade IV neutropenia resulting in hospitalization } \\
\hline $\begin{array}{l}\text { Chance of having a fever or infection requiring hospitalization with } \\
\text { intravenous antibiotics for } 3-5 \text { days. }\end{array}$ & $0 \%$ & $9 \%$ & $23 \%$ \\
\hline \multicolumn{4}{|l|}{ Grade III/IV mucositis/stomatitis } \\
\hline $\begin{array}{l}\text { Chance of sores and blisters in mouth that make eating and drinking painful; } \\
\text { may last I-2 weeks after receiving chemotherapy. }\end{array}$ & $0 \%$ & $5 \%$ & $10 \%$ \\
\hline \multicolumn{4}{|l|}{ Grade III/IV hand-foot syndrome } \\
\hline $\begin{array}{l}\text { Chance of tightness of the skin, peeling, sores and blisters on hands and } \\
\text { feet making it very painful to use them; may last } 7-14 \text { days after receiving } \\
\text { chemotherapy. }\end{array}$ & $0 \%$ & $5 \%$ & $12 \%$ \\
\hline \multicolumn{4}{|l|}{ Grade III/IV diarrhea } \\
\hline $\begin{array}{l}\text { Chance of more than } 6 \text { episodes of diarrhea per day, requiring intravenous } \\
\text { fluids at the hospital; may last } 2-5 \text { days after receiving chemotherapy. }\end{array}$ & $0 \%$ & $5 \%$ & $15 \%$ \\
\hline Efficacy & $\begin{array}{l}\text { Has not shown } \\
\text { an additional } \\
\text { survival benefit }\end{array}$ & $\begin{array}{l}\text { Has shown an } \\
\text { additional survival } \\
\text { benefit of I month }\end{array}$ & $\begin{array}{l}\text { Has shown an } \\
\text { additional survival } \\
\text { benefit of } 3 \text { months }\end{array}$ \\
\hline \multicolumn{4}{|l|}{$\begin{array}{l}\text { Regimen: frequency and duration of chemotherapy administration; } \\
\text { Six levels }\end{array}$} \\
\hline $\begin{array}{l}\text { Six levels } \\
\text { - } 2 \text { I-day cycle; oral tablets taken twice daily for first } 2 \text { weeks } \\
\text { - } 2 \text {-day cycle; } 2-5 \text {-minute infusion on days I and } 8 \\
\text { - } 21 \text {-day cycle; } 3 \text { hour infusion on day I } \\
\text { - } 28 \text {-day cycle; } 6 \text {-I0-minute infusion on days I, } 8 \text {, and I5 } \\
\text { - } 21 \text {-day cycle; } 30 \text {-minute infusion on days I, 8, and I5 } \\
\text { - } 21 \text {-day cycle; } 3 \text {-hour infusion on days I, } 8 \text {, and I5 }\end{array}$ & & & \\
\hline
\end{tabular}

\section{Analysis}

The conjoint data were analyzed using Sawtooth Software SSI Web (v 6.4; Sawtooth Software, Sequim, WA). Analysis of ACA data involved the combination of the initial rating (the acceptability questions in the first phase) and the paired comparison questions. Specifically, using the information from the initial rating questions, prior utilities were calculated. The average for each attribute was subtracted to center its values at zero. For example, desirability values 3, 2, and 1 would be converted to 1,0 , and -1 , respectively. These initial estimates are part-worths, where within each attribute the values have a mean of zero, and differences between values are proportional to differences in desirability ratings or rank orders of preference. With respect to the paired comparison questions, a column vector was created for the dependent variable as follows: the respondents' answers were zerocentered, where the most extreme lowest value was given -4 , and the most extreme highest value was +4 . Interior ratings 
were fitted proportionally within that range. Each pair's question contributed a row to both the independent variable matrix and dependent variable column vector. Ordinary least-square estimates of the $n$ attribute levels were computed by regression of the dependent variable column vector on the matrix of independent variables. The part-worth estimates based on the prior and paired comparison phases were normalized to have equal sums of differences between the best and worst levels of each attribute across all attributes. The two vectors of part-worths were added together, yielding final utilities for each attribute level for each respondent. The absolute values of the final utilities were arbitrary; what was important was the magnitude of difference between them. These weights were "zero-centered," whereby the utility weight of the attribute level falling in the middle had a value that approximated zero and the more favorable level was higher, or positive, and the less favorable level was lower, or negative. Finally, the Bayes approach was applied to the data to further refine the precision of the utility estimates.

The utilities enable the calculation of the relative importance of each attribute for each respondent in influencing treatment decisions. Specifically, the relative importance was calculated for each respondent by dividing the range for each attribute (utility of highest level-utility of lowest level) by the sum of ranges of all attributes for the respective individual and multiplying it by 100 . These estimates indicate how much the difference in importance between the best and worst levels of each attribute affects the decision to choose a treatment. These are ratio data, meaning for example that an attribute with an importance of $10 \%$ is twice as important as an attribute with an importance of $5 \%$.

Using the mean utility weights for the attribute levels, we compared the percentages of patients who would prefer the following scenarios differing with respect to selected attributes, while holding all other attributes constant: (1) three levels of efficacy (no additional survival, 1 month additional survival, and 3 months additional survival); (2) three regimens (most convenient [oral], least convenient [21-day cycle; 3-hour infusion on days 1, 8, and 15], and one in between [28-day cycle; 6-10 minute infusion on days 1, 8, and 15]); and (3) a $0 \%$ versus a $10 \%$ chance of each toxicity.

\section{Results}

Of 121 participants who completed the conjoint survey, $108(89 \%)$ were included in the final data analysis. Thirteen participants were excluded because their responses in the first section of the survey were illogical (eg, a participant rating a $24 \%$ chance of fatigue as more acceptable than a $0 \%$ chance) in at least two instances. Table 2 reports the demographic and clinical characteristics of the study population who were included in the analysis. The mean age was 50 years, with a mean time of 80 months since cancer diagnosis; $60 \%$ had attained at least a college-level education. With respect to treatment experience, about $35 \%$ of patients were on chemotherapy at the time of their participation in the study, and the mean time since the sample's last chemotherapy administration was approximately 19 months.

The mean utilities for each attribute level are presented in Table 3 (the actual values are arbitrary; the magnitude of the differences among them are what should be evaluated). In general, the utilities for each attribute level were ordered in the direction that was expected, where the most favorable attribute level had the highest utility and the least favorable level had the lowest. The efficacy attribute had the highest utility value for its most favorable level ("additional survival benefit of 3 months") and lowest utility value for its least favorable level ("no additional survival benefit"), with means of 97.05 and -83.77 , respectively. This finding indicates that patients view a change in survival advantage from $0 \%$ to 3 months as more important than a change from the least favorable to the most favorable level for all other attributes.

Figure 1 presents the "percentage importance" estimates for each attribute. Overall, the most important attributes in driving treatment preferences were survival advantage, neutropenia/hospitalization, and toxicities such as nausea/ vomiting, fatigue, and diarrhea. Least important attributes were the toxicities of mucositis/stomatitis, myalgia, and hand-foot syndrome. In general, the difference between the most inconvenient to the most convenient administration regimen was less important than a $13 \%$ chance or more of severe toxicities, but more important than a $10 \%-12 \%$ chance of severe toxicities. The exception to this finding was myalgia, which had a maximum level of $15 \%$ chance of occurring; the difference between $0 \%$ versus $15 \%$ chance of myalgia was still less important than the difference between the most inconvenient and most convenient regimen (percentage importances $=8.8 \%$ versus $3.2 \%$ ).

In sensitivity analyses, we created scenarios for each toxicity (ie, each attribute that was a side effect) in which we compared preferences for a $0 \%$ risk of that toxicity versus a $10 \%$ risk of that toxicity, holding the risk of all other toxicity attributes constant. Specifically, we obtained preference estimates for two product profiles in which one toxicity differed 
Table 2 Demographic and clinical characteristics

\begin{tabular}{|c|c|}
\hline Characteristic & $\begin{array}{l}\text { Study population } \\
(n=108)\end{array}$ \\
\hline Age, mean (SD) & $50.43(8.56)$ \\
\hline \multicolumn{2}{|l|}{ Stage, $n(\%)$} \\
\hline 1 & $20(18.5 \%)$ \\
\hline II & $33(30.6 \%)$ \\
\hline III & $18(16.7 \%)$ \\
\hline IV & $37(34.3 \%)$ \\
\hline Months since diagnosis, mean (SD) & $80(103.40)$ \\
\hline \multicolumn{2}{|l|}{ Race/ethnicity, n (\%) } \\
\hline Caucasian & $96(88.1 \%)$ \\
\hline African-American & $8(7.3 \%)$ \\
\hline Other & $5(5.0 \%)$ \\
\hline \multicolumn{2}{|l|}{ Highest education level, n (\%) } \\
\hline High school & $10(9.3 \%)$ \\
\hline Some college & $21(19.4 \%)$ \\
\hline College & $44(40.7 \%)$ \\
\hline Graduate & $32(29.6 \%)$ \\
\hline \multicolumn{2}{|l|}{ Employment status, n (\%) } \\
\hline Full-time & 48 (44.4\%) \\
\hline Part-time & $6(5.6 \%)$ \\
\hline Homemaker & $10(9.3 \%)$ \\
\hline Student & $2(1.9 \%)$ \\
\hline Disabled & $24(22.2 \%)$ \\
\hline Unemployed & $6(5.6 \%)$ \\
\hline Retired & $8(7.4 \%)$ \\
\hline Other & $3(2.8 \%)$ \\
\hline \multicolumn{2}{|l|}{ Relationship status, n (\%) } \\
\hline Single & 15 (I3.9\%) \\
\hline Married/partner & 69 (63.9\%) \\
\hline Divorced/separated & $22(20.4 \%)$ \\
\hline Widow & I $(0.9 \%)$ \\
\hline \multicolumn{2}{|l|}{ Current health overall, n (\%) } \\
\hline Excellent & $14(12.96 \%)$ \\
\hline Very good & $36(33.33 \%)$ \\
\hline Good & $35(32.41 \%)$ \\
\hline Fair & 21 (19.44\%) \\
\hline Poor & I (0.93\%) \\
\hline Currently on chemotherapy, n (\%) & $4 \mathrm{l}(34.8 \%)$ \\
\hline $\begin{array}{l}\text { Months since last chemotherapy } \\
\text { administration, mean (SD) }\end{array}$ & $18.6(22.2)$ \\
\hline \multicolumn{2}{|c|}{ Adverse events from chemotherapy, $n$ (\%) } \\
\hline Hair loss & 77 (95.1\%) \\
\hline Joint/muscle aches/pains & 72 (88.9\%) \\
\hline Diarrhea & $46(56.8 \%)$ \\
\hline Nausea & $6 \mathrm{I}(75.3 \%)$ \\
\hline Vomiting & $32(39.5 \%)$ \\
\hline Fatigue & 78 (96.3\%) \\
\hline Loss of nails/toenails & 27 (33.3\%) \\
\hline Neutropenia & 15 (18.5\%) \\
\hline Stomatitis & $37(45.7 \%)$ \\
\hline Hand-foot syndrome & $22(27.2 \%)$ \\
\hline Sensory neuropathy & 55 (67.9\%) \\
\hline Motor neuropathy & 31 (38.3\%) \\
\hline Hospitalization & 17 (21.0\%) \\
\hline None of the above & $0(0.0 \%)$ \\
\hline
\end{tabular}

Abbreviation: SD, standard deviation.
Table 3 Mean utilities of attribute levels ${ }^{\mathrm{a}}$

\begin{tabular}{|c|c|}
\hline Attribute & Mean (SE) \\
\hline \multicolumn{2}{|l|}{ Alopecia } \\
\hline $0 \%$ & $39.72(0.35)$ \\
\hline $48 \%$ & $-3.12(0.34)$ \\
\hline $94 \%$ & $-36.60(0.33)$ \\
\hline \multicolumn{2}{|l|}{ Myalgia } \\
\hline $0 \%$ & $19.03(0.16)$ \\
\hline $4 \%$ & $-0.02(0.13)$ \\
\hline $15 \%$ & $-19.01(0.17)$ \\
\hline \multicolumn{2}{|l|}{ Nausea and vomiting } \\
\hline $0 \%$ & $55.98(0.43)$ \\
\hline $4 \%$ & $1.95(0.65)$ \\
\hline $15 \%$ & $-57.92(0.47)$ \\
\hline \multicolumn{2}{|l|}{ Fatigue } \\
\hline $0 \%$ & $58.98(0.4 \mathrm{I})$ \\
\hline $8 \%$ & $0.43(0.54)$ \\
\hline $24 \%$ & $-59.41(0.53)$ \\
\hline \multicolumn{2}{|l|}{ Neutropenia/hospitalization } \\
\hline $0 \%$ & $81.21(0.34)$ \\
\hline $9 \%$ & $0.78(0.6 \mathrm{I})$ \\
\hline $23 \%$ & $-81.99(0.60)$ \\
\hline \multicolumn{2}{|l|}{ Mucositis } \\
\hline $0 \%$ & $25.61(0.17)$ \\
\hline $5 \%$ & $-1.25(0.10)$ \\
\hline $10 \%$ & $-24.37(0.14)$ \\
\hline \multicolumn{2}{|l|}{ Hand-foot syndrome } \\
\hline $0 \%$ & $34.07(0.18)$ \\
\hline $5 \%$ & $-2.35(0.18)$ \\
\hline $12 \%$ & $-31.72(0.19)$ \\
\hline \multicolumn{2}{|l|}{ Motor neuropathy } \\
\hline $0 \%$ & $35.36(0.23)$ \\
\hline $4 \%$ & $-3.31(0.22)$ \\
\hline $10 \%$ & $-32.05(0.26)$ \\
\hline \multicolumn{2}{|l|}{ Sensory neuropathy } \\
\hline $0 \%$ & $57.42(0.32)$ \\
\hline $7 \%$ & $-9.29(0.37)$ \\
\hline $13 \%$ & $-48.13(0.33)$ \\
\hline \multicolumn{2}{|l|}{ Diarrhea } \\
\hline $0 \%$ & $55.77(0.32)$ \\
\hline $5 \%$ & $-2.69(0.43)$ \\
\hline $15 \%$ & $-53.08(0.29)$ \\
\hline \multicolumn{2}{|l|}{ Regimen } \\
\hline $\begin{array}{l}\text { 21-day cycle; oral tablets taken twice daily for } \\
\text { first } 2 \text { weeks }\end{array}$ & $38.61(0.73)$ \\
\hline $2 \mathrm{I}$-day cycle; $2-5$-minute infusion on days $\mathrm{I}$ and 8 & $20.01(0.74)$ \\
\hline 2I-day cycle; 3-hour infusion on day I & $7.21(0.95)$ \\
\hline 28-day cycle; 6-10-minute infusion on days 1,8 , and 15 & $0.14(0.63)$ \\
\hline 2I-day cycle; 30-minute infusion on days I, 8 , and I5 & $-11.04(0.48)$ \\
\hline 2I-day cycle; 3-hour infusion on days I, 8, and I5 & $-54.92(0.37)$ \\
\hline \multicolumn{2}{|l|}{ Efficacy } \\
\hline Additional survival benefit of 3 months & $97.05(0.72)$ \\
\hline Additional survival benefit of I month & $-13.28(0.76)$ \\
\hline No additional survival benefit & $-83.77(0.65)$ \\
\hline
\end{tabular}

Note: aValues for each attribute are "0-centered" whereby the middle estimate approximates 0.0 and the other attribute values are estimated in relation to this middle value.

Abbreviation: SE, standard error. 


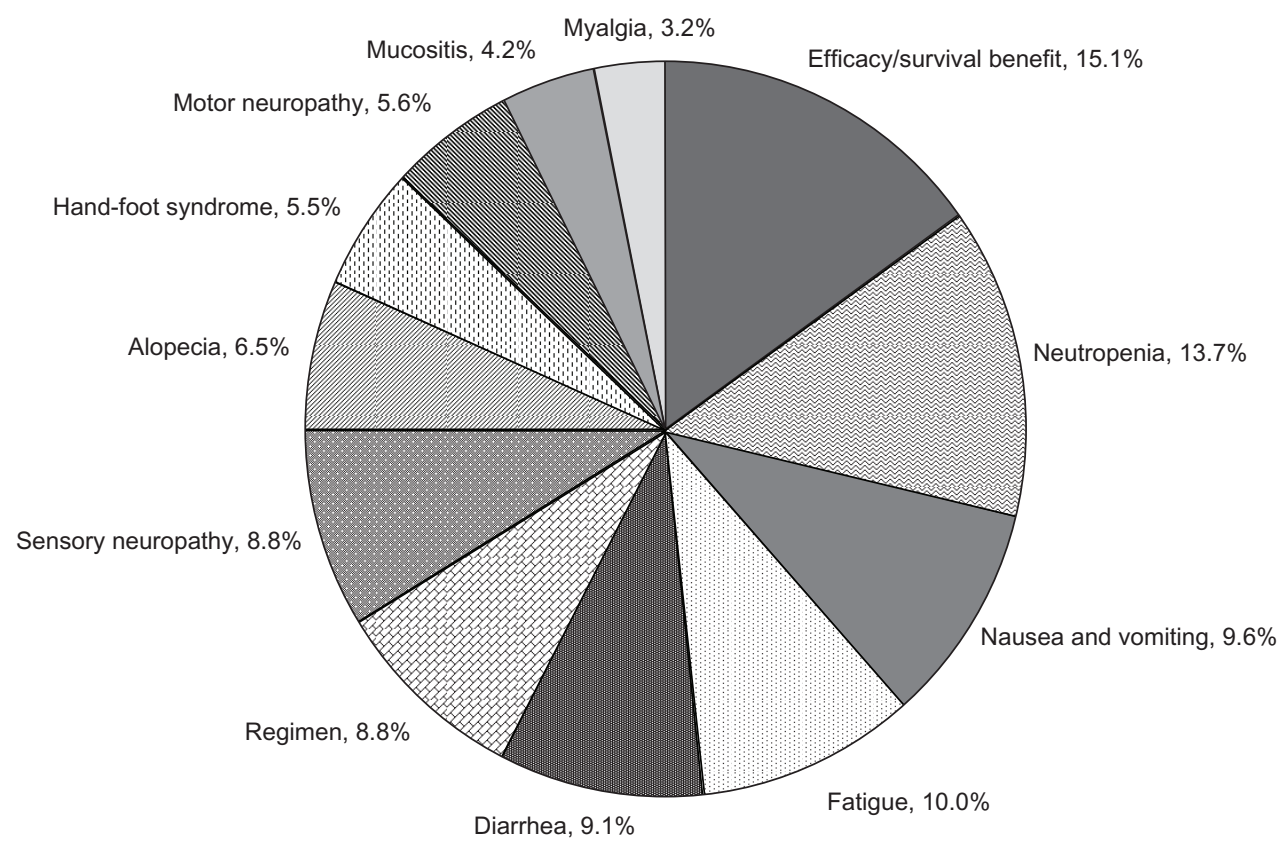

Figure I Relative importance of attributes*.

Note: *Ratio data: $10 \%$ is twice as important as $5 \%$.

by $10 \%$ and the remaining attributes were held constant; we repeated this for each side effect. Figure 2 shows the percentages of patients who would prefer a treatment given a $0 \%$ chance versus a $10 \%$ chance of each toxicity occurring. The findings show that patients most preferred to avoid neutropenia/hospitalization, diarrhea, nausea/vomiting, and sensory neuropathy (ie, they most preferred no risk of these toxicities relative to no risk of the other toxicities). An additional analysis found no substantial differences in relative importance estimates of toxicities between those who had experienced the side effect versus those who had not (data not shown).

Figure 3 presents the percentages of patients preferring each of three regimens that differ in efficacy (survival

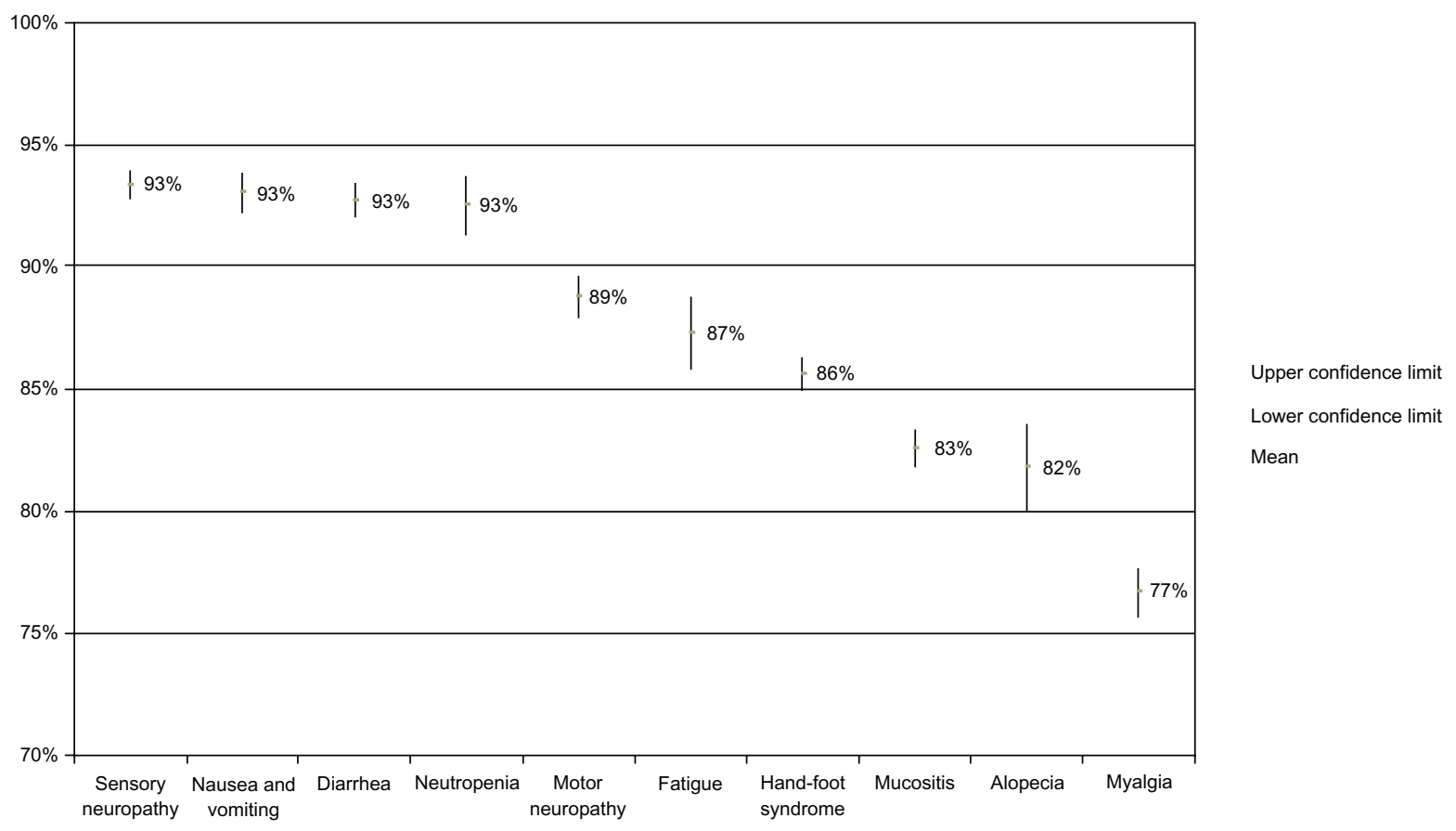

Figure 2 Percentages of patients preferring treatment given a $0 \%$ chance of the selected toxicity versus a $10 \%$ chance, holding all other attributes constant. 


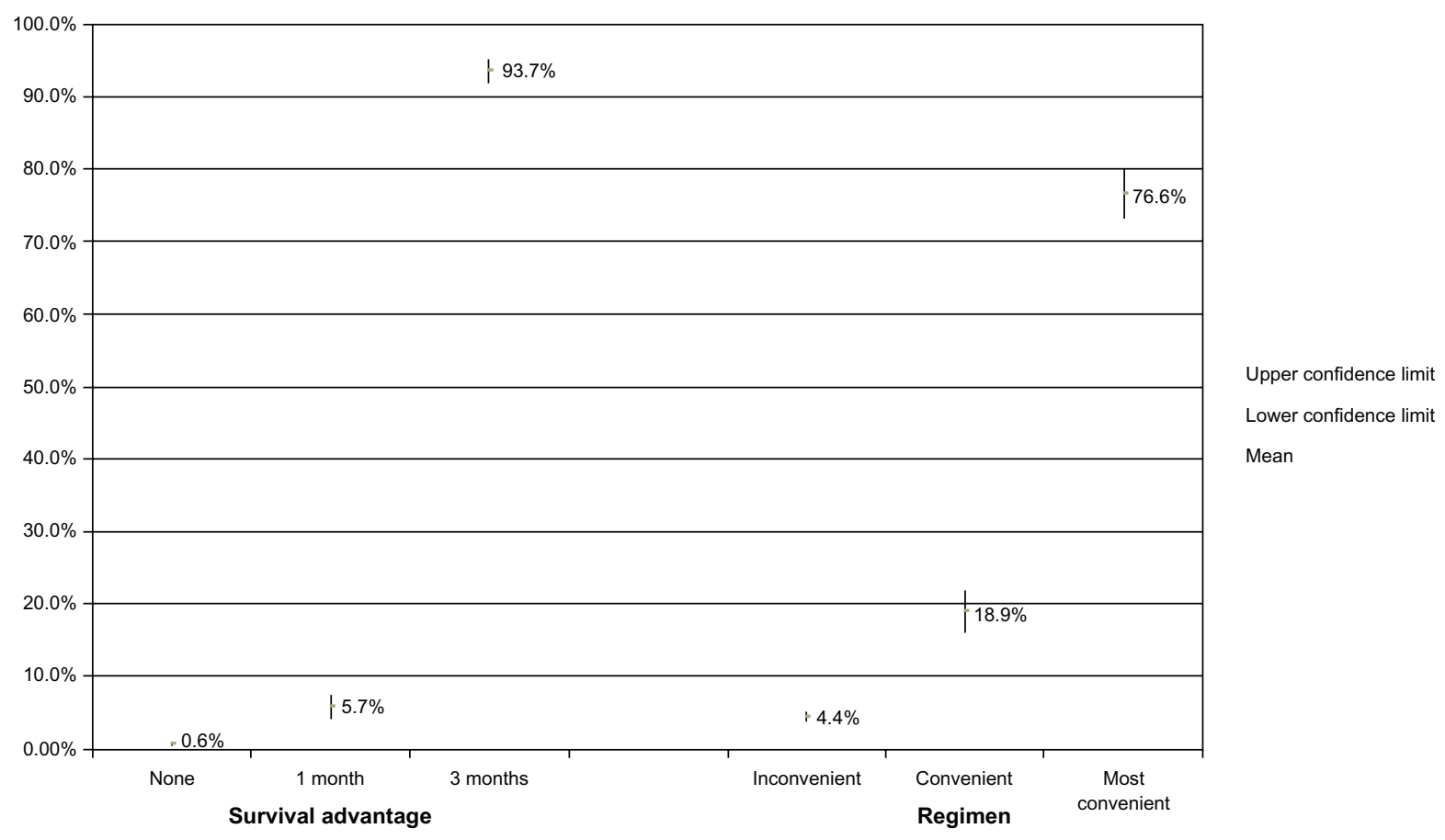

Figure 3 Percentages of patients preferring treatments with differences in survival advantage and differences in regimen convenience, holding all other attributes constant.

advantage) and the percentages of patients preferring three regimens, ie, an oral regimen, a regimen somewhat in "the middle" with respect to convenience (28-day cycle; 6-10 minute infusion on days 1,8 , and 15), and the most inconvenient (21-day cycle; 3 -hour infusion on days 1, 8, and 15). The findings show that the difference between a 1-month and 3-month survival advantage substantially influenced patient preferences; the percentages of patients preferring each of these regimens increased from 5.7\% to $93.7 \%$, respectively. Also, an oral regimen was highly preferred; $76.6 \%$ of patients would choose an oral regimen versus $18.9 \%$ who would choose the "middle" regimen.

\section{Discussion}

To the best of our knowledge, this study is the first to assess patient preferences for invasive breast cancer treatments considering a variety of treatment features. Specifically, this study assessed the trade-offs that breast cancer patients are willing to make among the risks of severe toxicities, administration regimen, and efficacy when choosing a chemotherapy. Among the chemotherapy attributes evaluated in this study, those that were most influential in driving patient preferences for treatment were improved survival, the risk of neutropenia leading to hospitalization, and the risks of severe fatigue, nausea and vomiting, and diarrhea. Least important were the risks of severe myalgia, mucositis, and hand-foot syndrome. The study findings are useful in better understanding patient preferences in oncology and may enhance the medical decision-making process.

For most patients, the difference between having no additional survival advantage and having a survival advantage of 3 months was about three times more important than an approximate $10 \%$ versus $0 \%$ risk of experiencing several severe toxicities, including severe myalgia, mucositis, hand-foot syndrome, and motor neuropathy. In addition, the incremental improvement in survival was one-and-a-half times as important as an approximate $15 \%-20 \%$ versus $0 \%$ risk of having severe nausea and vomiting, fatigue, diarrhea, or sensory neuropathy. The finding of the high relative importance of improved efficacy is consistent with previous conjoint analyses of medical therapies ${ }^{13,14}$ and a review of previous literature, ${ }^{15}$ which found that patients are willing to accept the risk of serious adverse events in exchange for improved efficacy. For example, Johnson et a ${ }^{12}$ evaluated the treatment perceptions among patients with multiple sclerosis, and they found that most patients indicated they are willing to accept risks of life-threatening adverse events in exchange for improvements in their health outcomes.

This study builds upon previous work that has examined rankings among chemotherapy side effects. ${ }^{16}$ Specifically, Sun et $a 1^{16}$ evaluated preferences for 27 different side effects among patients with ovarian cancer. They found that severe nausea and vomiting was the least preferred toxicity and that "numbness in hands/feet" was among the most 
distressful side effects. Similarly, the current study showed that patients would most want to avoid the chance of severe nausea and vomiting and the chance of severe numbness in the arms and legs (sensory neuropathy) among the various potential toxicities evaluated, assuming that they each had an equal chance of occurring.

Our study found no substantial differences in the relative importance of toxicities between those who had experienced the toxicity versus those who had not. This finding differed from a previous study that examined utility (time trade-off) estimates for chemotherapy-related ototoxicity, nephrotoxicity, and neurotoxicity among ovarian cancer patients. ${ }^{17}$ Specifically, the study found that the most favorable assessment of a particular toxicity was reported from individuals who experienced the selected toxicity. This may be attributable to the fact that patients were asked to assume that the toxicity was permanent; as such, patients with experience may have felt they could better tolerate the effect than naïve patients. In contrast, in the current study, each of the side effects had a specified duration, and thus this may not have been significant enough to translate into differences between those experienced versus not experienced with each toxicity. Moreover, our findings were consistent with the finding of no substantial differences observed in relative importance of eleven of 12 side effects between HIV treatment-experienced, who may have experienced treatment side effects, versus treatment-naïve patients. ${ }^{18}$

The current study also found that a more convenient administration regimen was more important to patients than severe side effects when the respective risk was less than $13 \%$. Similarly, improved convenience has been found to be influential in treatment choices in other studies. ${ }^{13,14}$ For example, in a study of patients with idiopathic thrombocytopenic purpura, patients were willing to accept significant treatment-related risks in exchange for improvements in treatment efficacy and convenient administration. ${ }^{13}$

Our study was not without limitations. First, each of our toxicity attributes was described using durations from a few days to 6 months after treatment end, and these durations represented clinical averages. These average durations may not be reflective of individual experiences, however, as our discussions with clinicians revealed that side effect experience is highly variable between patients. In addition, the participants in our sample did not represent the full range of breast cancer patients; the majority were well-educated, most were Caucasian, and they were all healthy enough to complete a computer-based survey at home. It is unclear whether the preferences of severely ill cancer patients (eg, those who are bedridden) or other ethnic groups would be different from those expressed by patients in our sample. Because of these limitations, while our study has yielded important findings with implications for the medical community, future research is necessary to evaluate the generalizability of our conclusions.

\section{Conclusion}

In summary, this survey evaluated a comprehensive set of severe toxicities and other features that are observed with chemotherapies for invasive breast cancer. Our study showed that, despite the risk of serious toxicities, a small incremental survival advantage is highly influential in patient preferences for chemotherapy. The findings from this research may be useful in incorporating patients' views into medical decision making processes, patient education, cost resource allocations, and drug development. A better understanding of patients' preferences may help to improve patient satisfaction and compliance with treatment regimens.

\section{Disclosure}

Kathy Beusterien and Jessica Grinspan are employed by Oxford Outcomes, Inc, an ICON plc company, which consults for Eisai, the study sponsor. Thomas Tencer is a former employee of Eisai, the study sponsor. Adam Brufsky and Constance Visovsky report no conflicts of interest in this work.

\section{References}

1. American Cancer Society. Breast cancer overview. Available from: http:// www.cancer.org/Cancer/BreastCancer/OverviewGuide/. Accessed June $1,2010$.

2. Ligibel JA. Breast cancer metastasis. HealthScout. Available from: http://www.healthscout.com/ency/68/484/main.html. Accessed June 1, 2010.

3. Mayer M. Treatments in common use for metastatic breast cancer. Available from: http://www.advancedbc.org/content/treatmentscommon-use-metastatic-breast-cancer-g. Accessed June 1, 2010.

4. Beusterien KB, Davies J, Leach M, et al. Population preference values for treatment outcomes in chronic lymphocytic leukaemia: a crosssectional utility study. Health Qual Life Outcomes. 2010;8:50.

5. Armstrong T, Almadrones L, Gilbert MR. Chemotherapy-induced peripheral neuropathy. Oncol Nurs Forum. 2005;32(2):305-311.

6. Sun CC, Bodurka DC, Donato ML, et al. Patient preferences regarding side effects of chemotherapy for ovarian cancer: do they change over time? Gynecol Oncol. 2002;87(1):118-128.

7. Green PE, Srinivasan V. Conjoint analysis in marketing: new developments with implications for research and practice. Journal of Marketing. 1990;54(4):3-19

8. Ryan M, Farrar S. Using conjoint analysis to elicit preferences for health care. BMJ. 2000;320:1530-1533.

9. US Department of Health \& Human Services. Health Information Privacy. Available from: http://www.hhs.gov/ocr/privacy. Accessed June 1, 2010.

10. Bridges JF, Hauber AB, Marshall D, et al. Conjoint analysis applications in health - a checklist: a report of the ISPOR GoodResearch Practices for Conjoint Analysis Task Force. Value Health. 2011;14(4):403-413. 
11. Green PE, Krieger AM, Agarwal MK. Adaptive Conjoint Analysis: some cautions and caveats. J Market. 1991;54:3-19.

12. Sawtooth Software. ACA/Web v6.0 Technical Paper. Sequim, WA: Sawtooth Software, Inc; 2007. Available from http://sawtoothsoftware. com. Accessed August 15, 2009.

13. Johnson FR, Van Houtven G, Ozdemir S, et al. Multiple sclerosis patients' benefit-risk preferences: serious adverse event risks versus treatment efficacy. J Neurol. 2009;256(4):554-562.

14. Hauber AB, Johnson FR, Grotzinger KM, Ozdemir S. Patients“ benefitrisk preferences for chronic idiopathic thrombocytopenic purpura therapies. Ann Pharmacother. 2010;44(3):479-488.

15. Sasane M, Tencer T, French A, Maro T, Beusterien KM. Patient reported outcomes in chemotherapy-induced peripheral neuropathy: A review. $J$ Support Oncol. 2010;8(6):e15-e21.
16. Sun CC, Bodurka DC, Weaver CB, et al. Rankings and symptom assessments of side effects from chemotherapy: insights from experienced patients with ovarian cancer. Support Care Cancer. 2005; 13:219-227.

17. Calhoun EA, Fishman DA, Lurain JR, Welshman EE, Bennett CL. A comparison of ovarian cancer treatments: analysis of utility assessments of ovarian cancer patients, at-risk population, general population, and physicians. Gynecol Oncol. 2004;93:164-169.

18. Beusterien KM, Dziekan K, Schrader S, et al. Patient preferences among third agent HIV medications: a US and German perspective. AIDS Care. 2007;19(8):982-988.

\section{Publish your work in this journal}

The International Journal of Women's Health is an international, peerreviewed open-access journal publishing original research, reports, reviews and commentaries on all aspects of women's healthcare including gynecology, obstetrics, and breast cancer. Subject areas include: Chronic conditions (migraine headaches, arthritis, osteoporosis);

\section{Dovepress}

Endocrine and autoimmune syndromes; Sexual and reproductive health; Psychological and psychosocial conditions. The manuscript management system is completely online and includes a very quick and fair peer-review system. Visit http://www.dovepress.com/ testimonials.php to read real quotes from published authors.

Submit your manuscript here: http://www.dovepress.com/international-journal-of-womens-health-journal 